doi: $10.15407 /$ ujpe63.01.0070

M.P. GORISHNYI, A.B. VERBITSKY

Institute of Physics, Nat. Acad. of Sci. of Ukraine

(46, Prosp. Nauky, Kyiv 03028, Ukraine; e-mail: miron.gorishny@gmail.com)

\title{
DONOR-ACCEPTOR INTERACTION IN FILMS OF TETRACENE-TETRACYANOQUINODIMETHANE HETEROSTRUCTURES AND COMPOSITES
}

\section{Introduction}

Tetracene (TC) is a high-resistance organic semiconductor of the $p$-type with a wide energy gap $E_{g} \geq$ $3.0 \mathrm{eV}$ [1]. The photovoltaic effect in TC crystals and films was studied in works [2-4]. The effective coefficient of conversion of the light energy into the electric one in solar cells with a TC/C60 (fullerene) heterostructure was found to equal $1.7-2.3 \%[5,6]$ or $0.34 \%$ [7]. Photo-electric properties of field-effect transistors [8-11] and light-emitting diodes [12-14] on the basis of TC crystals and films were also studied.

In 1960, a strong electron acceptor, tetracyanoquinodimethane (TCNQ), was synthesized for the first time [15]. Interest to this compound was invoked by

(C) M.P. GORISHNYI, A.B. VERBITSKY, 2018 the discovery of its highly conducting anion-radical salt (the CT complex) with tetrathiafulvalene (TTF) in 1973 [16]. The electron absorption and luminescence spectra of TCNQ and its anion-radicals were considered in works $[17,18]$ in detail. At the thermal sputtering in vacuum, the structure and electric properties of thin TCNQ films depend on the sputtering rate and the substrate temperature [19]. The switching effect was observed in $\mathrm{Me} / \mathrm{TCNQ}$ heterostructures, where $\mathrm{Me}=\mathrm{Cu}, \mathrm{Ag}$, and $\mathrm{K}$ [20-23]. It results from a drastic change of the conductivity in those heterostructures under the influence of the critical electric field. This effect can be used to manufacture electric switches. The electron absorption spectra and the electric properties of TCNQ/C60 heterostructures were studied in work $[24,25]$. The conductivity 
of copper phthalocyanine $(\mathrm{CuPc})$ and graphene films considerably increases after their doping with TCNQ molecules [26, 27].

The structure of TC + TCNQ cocrystals obtained from the vapor phase was also studied. The crystal lattice of those cocrystals consists of stacks, in which TC and TCNQ molecules alternate [28]. The calculated magnitude of charge transfer from the TC donor (with the $p$-type conductivity) to the TCNQ acceptor (with the $n$-type conductivity) amounts to $0.13 e$, where $e$ is the elementary charge, with good transport properties of those cocrystals taking place only for electrons [29]. A field-effect transistor with an average mobility of about $10^{-4} \mathrm{~cm}^{2} /(\mathrm{V} \mathrm{s})$ and a switch on/off ratio of about $10^{5}$ was created on the basis of TC + F4TCNQ cocrystals. Furthermore, those cocrystals reveal quite a good photo-response in the "switch on" and "switch off" regimes [30].

The analysis of the literature data, including those cited above, showed that the description of the absorption and photovoltaic spectra of TC/TCNQ heterostructures and TC + TCNQ composites, as well as the manifestations of the donor-acceptor interaction in those spectra, is almost absent. The corresponding research is required for a deeper understanding of the operation principles of probable devices on the basis of the indicated heterostructures and composites. This is the aim of this work.

\section{Experimental Technique}

Thin TC and TCNQ films, as well as heterostructures with planar (PHJ) and bulk (BHJ) heterojunctions, respectively, were fabricated in a vacuum of $6.5 \mathrm{mPa}$ by thermally sputtering the corresponding substance onto glass substrates covered with a conducting ITO layer. The masses of TC or TCNQ loaded into a crucible when preparing a single-component films and heterostructures amounted to 13 and $10 \mathrm{mg}$, respectively. In the heterostructures with the PHJ (below, the heterostructures or TC/TCNQ), the TC layer was located lower and the TCNQ one upper with respect to each other. The heterostructures with the BHJ (below, the composites or TC + TCNQ) were fabricated, by thermally sputtering a mixture of $\mathrm{TC}$ and TCNQ from a ceramic crucible. The film thickness was measured, by using an MII-4 interference thickness gauge. The absorption spectra were registered with the help of a Perkin Elmer Lambda $25 \mathrm{uv} /$ vis spectrophotometer with a spectral width of $1 \mathrm{~nm}$ and at room temperature. The measurement error did not exceed $2 \%$.

A measurement cell was formed by two glass substrates. One side of each substrate was covered with a conducting ITO layer, whereas the other remained clean. The TC (or TC/TCNQ) or TCNQ (or TC + + TCNQ) films were sputtered on the substrate side that had been covered with the ITO layer (the rear electrode). The free surface of those films and the ITO layer on the other substrate (the front electrode) were separated by a teflon film $20 \mu \mathrm{m}$ in thickness. One substrate was carefully imposed on the other, so that their covered surfaces were inside and with a relative shift of $3 \mathrm{~mm}$ in order to create contact platforms for output conductors. Afterward, the electrodes were strongly pressed to each other, and their edges were covered with a thin film of epoxy resin. After the resin had hardened, thin copper conductors in the teflon isolation were soldered by indium to the ITO layers of contact platforms. The system obtained could be regarded as a static condenser, in which the free surfaces of the indicated films and the ITO layer of the second substrate were the plates, and the teflon film played the role of an insulator. The area of the plates of this condenser amounted to $120 \mathrm{~mm}^{2}$, and its theoretical static capacitance was $106 \mathrm{pF}$. Under the modulated light illumination at a frequency of $80 \mathrm{~Hz}$, the cell impedance $Z_{\mathrm{c}}$ did not exceed the cell capacitance and amounted to $19 \mathrm{M} \Omega$.

Light emitted by an 120-W iodine incandescent lamp (Hitachi) was directed through a focusing system consisting of two quartz lenses, a modulator, and a corresponding light filter to an MDR-4 monochromator (LOMO). Monochromatic light from the output slit of MDR-4 was focused on a window in the vacuum cell. The researched specimen was mounted at the center of this cell. The photo-emf $V$ was measured with the help of a phase-sensitive selective nanovoltmeter 232B (Unipan) equipped with an preamplifier 233-7 (Unipan) at the input and a grounded cell screen. From the output of a nanovoltmeter, the signal was directed to a personal computer through an interface card ET-1050. The preamplifier impedance $Z_{\text {a }}$ amounted to $1 \mathrm{G} \Omega$. Therefore, the magnitude of $V$ was measured in the idling mode, since $Z_{\mathrm{a}} \gg Z_{\mathrm{c}}$. The installation made it possible to measure the changes of $V$ with the lifttime $\tau \leq 1 \mathrm{~s}$. 
<smiles>c1ccc2cc3cc4ccccc4cc3cc2c1</smiles>

tetracene

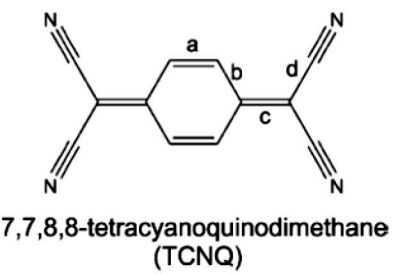

Fig. 1. Structural formulas of TC and TCNQ molecules [28]

The reference signal was created, by using a photon-coupled pair "light-emitting diode-photo diode", which was mounted at a modulator.

After every measurement series, the spectral distribution of the lamp intensity was measured with the help of a pyroelectric radiation sensor (the Special Design and Engineering Bureau at the Institute of Physics, Kyiv), which was mounted instead of the specimen, and the registered $V$-spectra were renormalized to the same number of incident light

Structures of TC, TCNQ, TC/TCNQ

heterostructure, and TC + TCNQ composite films sputtered onto glass substrates covered with an ITO layer. Images were obtained in an optical microscope at a 40x magnification and in polarized light (panels 1 to 3 ) and in an electron microscope (panels 4 to 7)

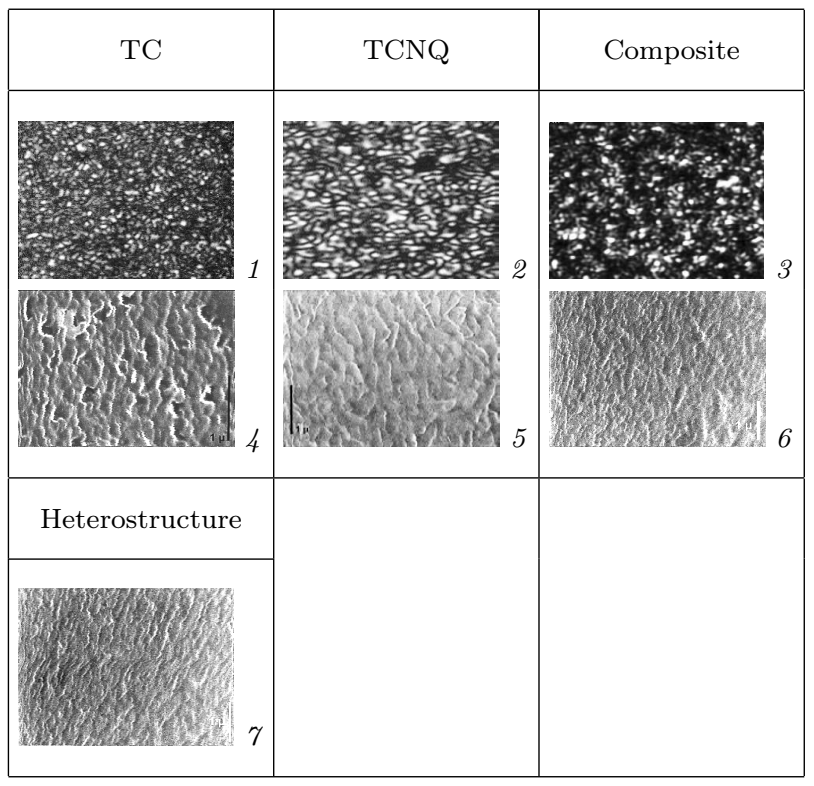

quanta. The measurement error for the photo-emf $V$ did not exceed $5 \%$.

The structures of all films were studied on an optical microscope Pernal Interphako (Carl Zeiss) and a scanning electron microscope JSM-35 (JEOL).

\section{Experimental Data}

The electron subsystems of the TC and TCNQ molecules (Fig. 1) have their specific features. The TC molecule is characterized by the delocalization of external $\pi$-electrons belonging to the carbon atoms $\mathrm{C}$, which occurs along the molecule perimeter formed by four benzene rings. In the TCNQ molecule, similar electrons can move between the opposite cyanogroups (CN groups) along bonds d, c, b, and a. The acceptor properties of the TCNQ molecule are determined by $\mathrm{CN}$ groups, which can capture external electrons or polarize the corresponding electron orbitals (the partial charge transfer) of the TC molecule in the course of interaction between the molecules.

In the optical microscope (see Table) at a 40x magnification and in polarized light, we observed a polycrystalline structure in the TC, TCNQ, and TC + TCNQ films (cells 1-3). The computer analysis showed that the crystallite size did not exceed $1 \mu \mathrm{m}$. The brightness of crystallites changed, when the polarizer was rotated around the vertical microscope axis. This fact testifies to different orientations of the optical axes of crystallites with respect to the glass substrate plane.

In the electron microscope, one can see that the TC films are porous (cell 4), and the TCNQ ones are continuous (cell 5). In the both cases, the films are polycrystalline.

The temperature of sublimation in vacuum amounts to $383 \mathrm{~K}$ for TCNQ [31] and $413-433 \mathrm{~K}$ for TC [32]. This fact means that if those substances are thermally sputtered from the same crucible and the crucible temperature increases, TCNQ will start first to sublimate. From a certain moment, those components will sublimate together, which is a necessary condition for the TC + TCNQ cocrystallites to be formed. Crystallites in the TCNQ film had a round shape. At the same time, TCNQ crystallites in the heterostructure (TC/TCNQ) films (cell 7) were oriented in the same direction, and their shape was mainly needle-like. This change of the crystallite shape is associated with the influence of a layer 
of TC molecules, when TCNQ molecules were sputtered onto it. In the composites (cell 6), chaotically oriented needle-like and round crystallites were observed. We may assume that, when TC and TCNQ are sublimated from the same crucible, the composite films containing TC and TCNQ crystallites, as well as TC + TCNQ cocrystallites, are formed.

The absorption spectra of TC, TCNQ, TC/TCNQ, and TC + TCNQ films were approximated by the sum of Gaussians, by using the Origin software. The approximation results were used to specify the positions of maxima of separate bands that form the structure of absorption bands.

In Fig. 2, the absorption spectra of the TC and TCNQ films $170 \mathrm{~nm}$ in thickness and the heterostructure film with a thickness of $170 \mathrm{~nm}$ for each layer are depicted. The absorption spectra for the heterostructure (curve 2) and TC (curve 4) films correlate with each other. The wide structural absorption band for the TC film corresponds to the first electron transition in the TC molecule. The long-wave bands at 2.340 and $2.460 \mathrm{eV}$ are the components of the Davydov splitting of the $0 \rightarrow 0$ transition, and they testify to the presence of a crystalline phase in the TC films [4]. The bands at 2.622, 2.799, and $2.963 \mathrm{eV}$ belong to the vibronic progression $0 \rightarrow n$, where $n=1,2$, and 3 . The absorption spectra of TCNQ films (curve 3) demonstrate bands at 2.214, 2.627, $2.714,2.816$, and $3.087 \mathrm{eV}$. On the long-wave slope of the band at $2.214 \mathrm{eV}$, we found a weak band at $1.978 \mathrm{eV}$. The bands at 3.087, 2.816, and $2.627 \mathrm{eV}$ are associated with the light absorption by neutral $\mathrm{TCNQ}^{0}$ molecules, $\mathrm{TCNQ}^{-}$anion-radicals, and $\mathrm{TCNQ}^{2-}$ dianions, respectively $[17,18]$. At the same time, the band at $2.714 \mathrm{eV}$ can be a vibrational repetition of the band at $2.627 \mathrm{eV}$. The bands at 2.214 and $1.978 \mathrm{eV}$ can be regarded as dimeric, because they are close by their positions to the $1.928-\mathrm{eV}$ band of the dimer of anion-radicals $\left(\mathrm{TCNQ}^{-}\right)_{2}$ in TCNQ aqueous solutions $[18,33]$.

The sum of the absorption spectra of the TC and TCNQ films (curve 1) differs substantially from the heterostructure film spectrum (curve 2). Curve 5 is the difference $\Delta D_{1}$ between the optical densities of curves 2 and 1 . One can see that $\Delta D_{1}<0$ in a spectral interval of $1.578-2.330 \mathrm{eV}$ and anticorrelates with the absorption behavior in the TCNQ film (curve 3, the band at $2.214 \mathrm{eV}$ ). In the interval $2.330-2.607 \mathrm{eV}$, $\Delta D_{1}>0$ and correlates with the absorption in the

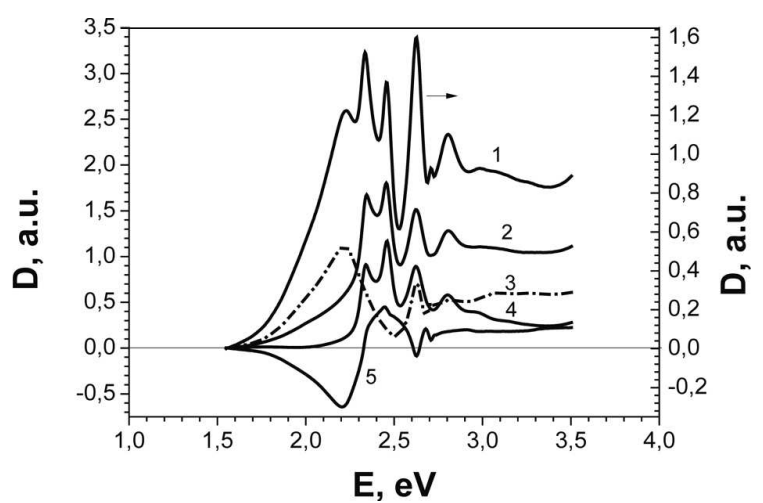

Fig. 2. Absorption spectra of TC (4) and TCNQ (3) films $170 \mathrm{~nm}$ in thickness, their sum (1), absorption spectrum of TC/TCNQ heterostructure (2), and difference $\Delta D_{1}$ between curves 2 and 1 (5)

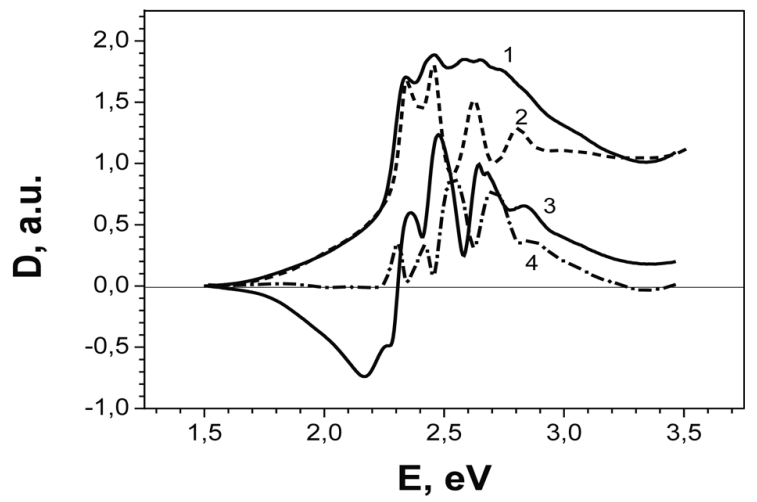

Fig. 3. Absorption spectra of films of TC + TCNQ composite (1), TC/TCNQ heterostructure (2), their difference $\Delta D_{2}$ (4), and difference $\Delta D_{1}$ between curves 1 and curves 1 (Fig. 2) (3)

TC film (curve 4). The anticorrelation is also observed between the absorption maxima for the TC $(2.622 \mathrm{eV})$ and TCNQ (2.627 and $2.714 \mathrm{eV})$ films. In the interval from 2.654 to $3.500 \mathrm{eV}$, the values of $\Delta D_{1}$ are positive $\left(\Delta D_{1}>0\right)$.

Figure 3 illustrates the absorption spectra of the composite film $170 \mathrm{~nm}$ in thickness (curve 1) and the heterostructure film with a thickness of each layer of $170 \mathrm{~nm}$ (curve 2), their difference $\Delta D_{2}$ (curve 4), and the difference $\Delta D_{1}$ between the absorption spectrum of the composite and the sum of the absorption spectra of the components (curve 3 ). The bands at $1.989,2.216,2.344,2.455,2.622,2.799$, and $3.025 \mathrm{eV}$ were revealed in the absorption spectrum of the heterostructure (curve 2), and at 2.015, 2.219, 2.341, 


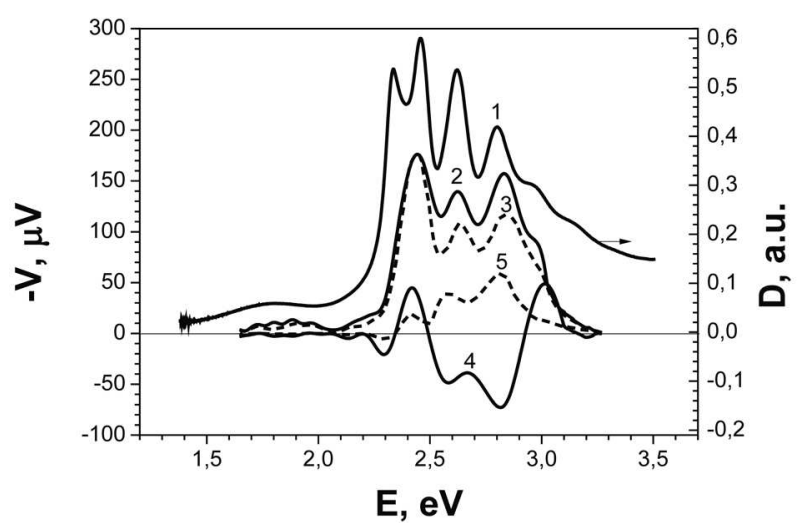

Fig. 4. Spectra of front, $V_{f}$ (2 and 3), and rear, $V_{r}(4$ and 5 ), condenser photo-emfs, and the absorption spectrum of the TC film $120 \mathrm{~nm}$ in thickness (1). Curves 2 and 4 were registered at the normal atmospheric pressure, and curves 3 and 5 at an air pressure of $100 \mathrm{~Pa}$ in the measurement cell

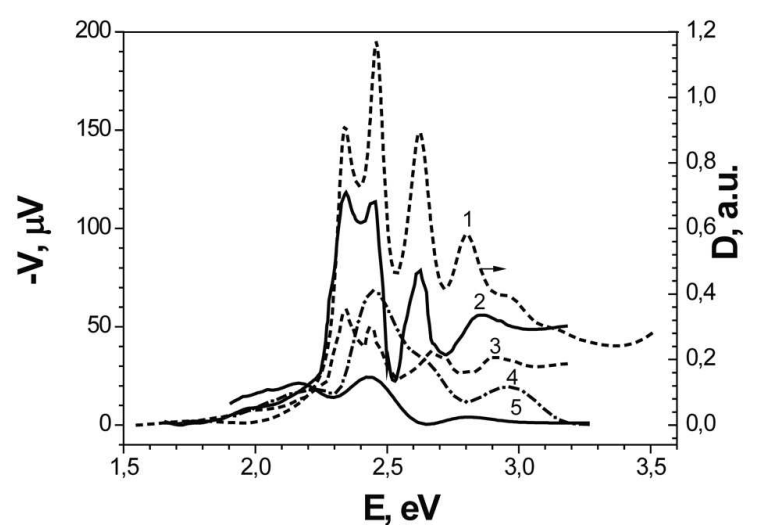

Fig. 5. Spectra of front, $V_{f}$ (2 and 4), and rear, $V_{r}$ (3 and 5 ), condenser photo-emfs, and the absorption spectrum of the TC film (1). Curves 1, 2, and 3 correspond to a film thickness of $170 \mathrm{~nm}$, and curves 4 and 5 to a filn thickness of $200 \mathrm{~nm}$

$2.456,2.578,2.646,2.717,2.820,2.977,3.141$, and $3.240 \mathrm{eV}$ in the absorption spectrum of the composite (curve 1). The spectrum for the difference $\Delta D_{2}$ (curve 4) anticorrelates with the absorption spectrum for the heterostructure (curve 2), and with the bands at 2.627 and $2.816 \mathrm{eV}$ for the TCNQ and TC films (Fig. 2, curves 3 and 4, respectively). The signs of $\Delta D_{1}$ for the composite (curve 3) and heterostructure (Fig. 2, curve 5) films are the same. Hence, the absorption spectra of the heterostructure and composite films reveal all bands inherent to their components (TC and TCNQ).
When analyzing the photovoltaic response of the TC, heterostructure, and composite films, one has to take into account that the experimental technique described above registers the signs of the charge at the front ITO electrode and the total charge at the free surface and in the space charge region (SCR) near this film surface.

The photovoltaic effect in the TC films depends on their thickness and the air pressure in the measurement cell (Figs. 4 and 5). At the illumination of the free surface of the TC film $120 \mathrm{~nm}$ in thickness at the normal atmospheric pressure, the front photo-emf $V_{f}<0$ (Fig. 4, curve 2), and it correlates with the absorption spectrum (curve 1). The spectrum of the front photo-emf demonstrates the shortwave Davydov-splitting component at $2.441 \mathrm{eV}$ and the vibronic bands at 2.622, 2.833, and $2.970 \mathrm{eV}$. The rear photo-emf $V_{r}$ (the illuminated film surface that directly contacts with the rear ITO electrode and is opposite to the free surface) changes its sign $\left(V_{r}>0\right)$ in the spectral intervals $2.201-2.348 \mathrm{eV}$ and $2.495-$ $2.927 \mathrm{eV}$ (curve 4). The bands at $2.422 \mathrm{eV}$ (Davydovsplitting component) and $3.01 \mathrm{eV}$ (the third vibronic band) have a negative sign. When the air pressure in the measuremwnt cell was lowered down to $100 \mathrm{~Pa}$, the rear photo-emf became negative $\left(V_{r}<0\right)$ everywhere, except for a weak band at $2.300 \mathrm{eV}$ (curve 5).

In the $V_{f}$ and $V_{r}$ spectra of the TC film $170 \mathrm{~nm}$ in thickness, the both components are observed (Fig. 5, curves 2 and 3). At the same time, only the shortwave component (curves 4 and 5) of the Davydov splitting is observed for the 200-nm film. The $V_{f}$ spectrum correlates with the absorption spectrum of the 170-nm film (curve 1). The analysis of the $V_{f}$ and $V_{r}$ spectra showed that the peak values of both photo-emfs diminish with the growth of the TC film thickness.

In Fig. 6, the $V_{f}$ (curves 2 and 3), $V_{r}$ (curves 4 and 5 ), and absorption spectra of heterostructure films with a thickness of $120 \mathrm{~nm}$ for each component layer are shown. In the $V_{f}$ spectra registered at the normal atmospheric pressure (curve 2) and at an air pressure of $100 \mathrm{~Pa}$ (curve 3), only the short-wave Davydovsplitting component in $\mathrm{TC}$ at $2.446 \mathrm{eV}$ and the bands at $2.617,2.823,2.995$, and $3.157 \mathrm{eV}$ are observed. Furthermore, if the air pressure in the measurement cell decreases, the intensities of those bands also diminish. In the $V_{r}$ spectra registered at the normal atmospheric pressure (curve 4) and at an air pressure 
of $100 \mathrm{~Pa}$ (curve 5), the long-wave Davydov-splitting component in TC at $2.343 \mathrm{eV}$ and the bands at 2.553, 2.843 , and $3.048 \mathrm{eV}$ reveal themselves. The intensities of those bands also decrease if the air pressure in the measurement cell becomes lower.

In Fig. 7, the $V_{f}$ (curve 1), $V_{r}$ (curve 3), and absorption (curve 2) spectra of composite films are depicted. The $V_{f}$ (the stronger signal) and $V_{r}$ (the weaker signal) spectra for the heterostructure with a thickness of component layers of $170 \mathrm{~nm}$ are exhibited in the inset. In the $V_{f}$ spectrum of the composite (curve 1), instead of the Davydov-splitting components (curve 2), one can observe bands at 2.567 and $2.896 \mathrm{eV}$, and an intensive band at $2.402 \mathrm{eV}$, which position is close to the short-wave component of splitting in TC. Additionally, this spectrum includes the long-wave low-intensity bands at 1.737 , $1.809,1.867,1.951,2.021$, and $2.205 \mathrm{eV}$, and the band at $2.157 \mathrm{eV}$. The $V_{r}$ spectrum of composite (curve 3) contains the band of the short-wave Davydov-splitting component (at $2.481 \mathrm{eV}$ ) and the bands at 2.656, 2.859, and $3.040 \mathrm{eV}$. The intensities of long-wave bands in the interval $1.7-2.3 \mathrm{eV}$ are lower that the corresponding intensities of the $V_{f}$ spectrum. In the $V_{f}$ spectrum of the heterostructure (the inset in Fig. 7, the stronger signal), the band of the long-wave Davydov-splitting component in TC is observed at $2.352 \mathrm{eV}$, as well as the bands at 2.537, 2.828 , and $3.052 \mathrm{eV}$ together with long-wave lowintensity bands. This spectrum also demonstrates the bands at $2.405,2.590$, and $2.961 \mathrm{eV}$. The $V_{r}$ spectrum of the heterostructure consists of the bands at 2.405, 2.577 (a vibronic repetition), and $2.947 \mathrm{eV}$.

The research of the photovoltaic response in TCNQ films showed that this parameter is too small and comparable with the measurement errors.

\section{Discussion of the Results Obtained}

The analysis of the absorption spectra of the TC, TCNQ, heterostructure, and composite films (Figs. 2 and 3 ) showed that the additivity rule is not satisfied. The largest deviations from this rule (see Fig. 2, curve 5) were observed in the regions of absorption band maxima in TCNQ $(2.214 \mathrm{eV}$, the dimeric band) and TC (2.340 and $2.460 \mathrm{eV}$, the bands of the Davydov-splitting components) films, with $\Delta D_{1}<0$ in the former case, and $\Delta D_{1}>0$ in the latter one. Similar variations were observed in the

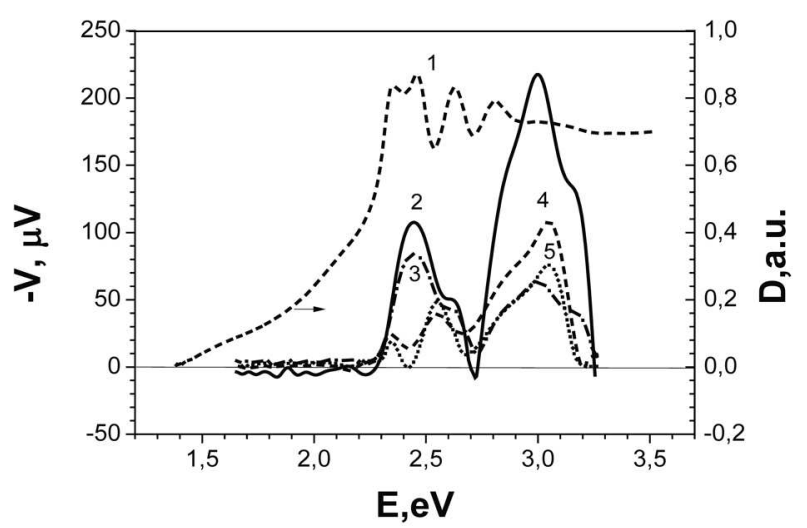

Fig. 6. Spectra of front, $V_{f}(2$ and 3$)$, and rear, $V_{r}$ (4 and $5)$, condenser photo-emfs, and the absorption spectrum of the TC/TCNQ heterostructure film (1). The thickness of each component layer equals $120 \mathrm{~nm}$. Curves 2 and 4 were registered at the normal atmospheric pressure, and curves 3 and 5 at an air pressure of $100 \mathrm{~Pa}$ in the measurement cell

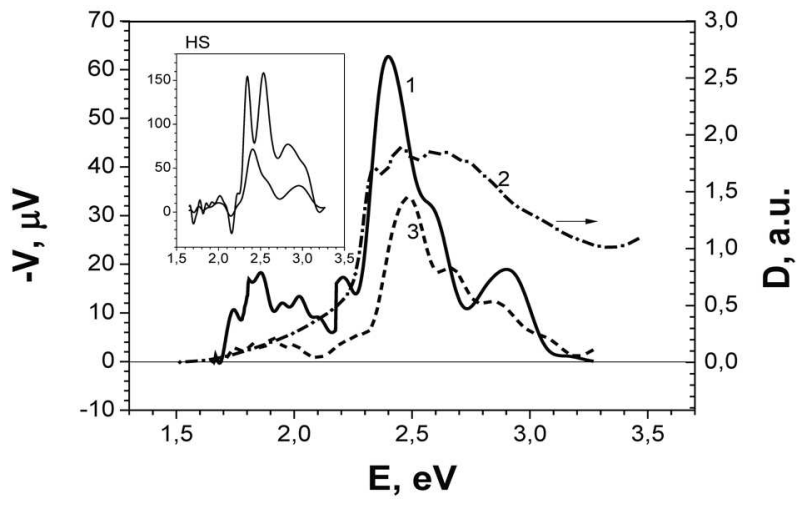

Fig. 7. Spectra of front, $V_{f}(1)$, and rear, $V_{r}$ (3), condenser photo-emfs, and the absorption spectrum of the TC + TCNQ composite film (2). The inset demonstrates the $V_{f}$ (larger signal) and $V_{r}$ (smaller signal) spectra for the TC/TCNQ heterostructure with a thickness of $170 \mathrm{~nm}$ for each component layer

absorption spectra of the composite, in which those molecules interact in the bulk (Fig. 3, curve 3). Furthermore, the maxima of the $\mathrm{TCNQ}^{2-}$ absorption bands and the first vibronic band of TC in the composite become shifted bathochromically by $0.044 \mathrm{eV}$ and hypsochromically by $0.024 \mathrm{eV}$ with respect to their position at $2.622 \mathrm{eV}$ in the heterostructure films (Fig. 3, curves 1 and 2, respectively). Those changes of $\Delta D_{1}$, which are larger than the measurement error, testify to the donor-acceptor interaction of $\mathrm{TC}$ molecules (donor) with closely located $\mathrm{TCNQ}^{0}$ and 
$\mathrm{TCNQ}^{-}$molecules (electron acceptors) at the interface between the components in the heterostructure and in the composite bulk. The $\mathrm{TCNQ}^{-}$molecules are formed in the former case, and the $\mathrm{TCNQ}^{2-}$ ones in the latter case. A additional proof of the donoracceptor interaction between the TC and TCNQ molecules is the appearance of the bands at 1.737 and $2.021 \mathrm{eV}$ in the $V_{f}$ and $V_{r}$ spectra of composites and heterostructures (Fig. 7), which, by their location, are close to the bands of $\mathrm{TC}^{+}$cation-radical at 1.67 and $2.06 \mathrm{eV}$ [34], as well as the bands at 2.828 and $2.896 \mathrm{eV}$ in the $V_{f}$ spectra of the heterostructure and the composite, which belong to the TCNQ ${ }^{-}$ anion-radical.

The ratio between the numbers of molecules of the electron donor and acceptor (TC and TCNQ, respectively) for the fabricated composites was found from the formula

$\frac{N_{1}}{N_{2}}=\frac{m_{1}}{m_{2}} \times \frac{M_{2}}{M_{1}}$

where $N_{1}, m_{1}=13 \mathrm{mg}$, and $M_{1}=228.29 \mathrm{~g} / \mathrm{mol}$ are the number of molecules, the sputtered mass, and the molar mass of TC, respectively, and $N_{2}, m_{2}=$ $=10 \mathrm{mg}$, and $M_{2}=204.19 \mathrm{~g} / \mathrm{mol}$ are the corresponding parameters for TCNQ. The resulting ratio calculated from this formula amounts to $N_{1}: N_{2}=$ $=1.16: 1.00$.

Thus, in the composites, there is one acceptor molecule per one donor molecule, which is a required condition for the emergence of CT complexes, when TC and TCNQ are simultaneously sputtered in vacuum. Furthermore, those complexes can also be created in the heterostructures at the interface between the components. The presence of such complexes is confirmed by the deviations, considered above, from the additivity rule in the absorption spectra of heterostructures and composites at 2.214, 2.340, 2.460, and $2.677 \mathrm{eV}$ (see Fig. 2, curve 5; and Fig. 3, curve 3) and by the appearance of the bands of $\mathrm{TC}^{+}$cationradical in those spectra.

Before analyzing the spectra of condenser photoemf $V$, we have to consider the type of electric conductivity in the TC, heterostructure, and composite films, and estimate the size of the charge photogeneration region in them.

Holes are the majority charge carriers in TC crystals and films $[1,4,32]$. The conductivity of the crystals of TCNQ ion-radical salts is realized by means of the electron transfer along the linear stacks of $\mathrm{TCNQ}^{-}$anion-radicals and holes along the alternative stacks of cation-radicals of various nature [35]. If the cation-radicals are alkaline metals (K, Cs), the conductivity of those salts is provided by the transfer of only electrons along the $\mathrm{TCNQ}^{-}$stacks [36]. The TCNQ salt has a high conductivity $\left(10^{2} \Omega^{-1} \mathrm{~cm}^{-1}\right)$, if those stacks are only created by anion-radicals with the same intermolecular distance of $0.326 \mathrm{~nm}$ between them. If $\left(\mathrm{TCNQ}^{-}\right)_{2}$ dimers and neutral $\mathrm{TCNQ}^{0}$ molecules alternate in the stacks, the salt has a low conductivity of $10^{-4} \Omega^{-1} \mathrm{~cm}^{-1}$. Dimer bands manifest themselves in the absorption spectra of crystals and pressed powders of low-conducting salts, and they are absent in the spectra of high-conducting salts $[37,38]$. The mechanisms of $\mathrm{TCNQ}^{-}, \mathrm{TCNQ}^{+}$, and $\mathrm{TCNQ}^{2-}$ formation in TCNQ stacks were described in work [39]. We may assume that electrons and holes in TC + TCNQ cocrystals move along the stacks of $\mathrm{TCNQ}^{-}$and TC molecules, respectively.

The photogeneration region of nonequilibrium charge carriers in the TCNQ and TC films, as well as in the films of their heterostructures and composites, can be estimated by the light penetration length $L_{a}$. This parameter is determined by the formula

$L_{a}=\frac{d}{D}$

where $d$ is the thickness, and $D$ the optical density of the film.

From the data of absorption spectra registered for the TC films (Figs. 4 and 5, curve 1) and formula (2), the following minimum values of $L_{a}$ were obtained: $200 \mathrm{~nm}$ for $d=120 \mathrm{~nm}, 146 \mathrm{~nm}$ for $d=170 \mathrm{~nm}$, and $144 \mathrm{~nm}$ for $d=200 \mathrm{~nm}$. It should be noted that the absorption spectra of the TC film $200 \mathrm{~nm}$ in thickness were given in work [4]. Hence, for the TC film $120 \mathrm{~nm}$ in thickness, $L_{a}$ exceeds the film thickness $d$ in the spectral interval $1.6-3.5 \mathrm{eV}$. The same relationship between $L_{a}$ and $d$ is also characteristic of the TC films 170 and $200 \mathrm{~nm}$ in thickness, except for narrow spectral intervals near the intensive maxima at 2.344 and $2.461 \mathrm{eV}$, where $L_{a} \leq d$. This fact means that the photogeneration of nonequilibrium charge carriers in TC films with all examined thicknesses took place simultaneously in the bulk and at their free and rear surfaces under both frontal and back illumination.

At the frontal illumination of the TC/TCNQ heterostructures, light firstly passes through the TCNQ

ISSN 2071-0194. Ukr. J. Phys. 2018. Vol. 63, No. 1 
layer, then through the interface between the components, and finally through the TC layer. We evaluated the ratio $L_{a} / d$ on the basis of formula (2) and the ratio $I / I_{0}$, where $I_{0}$ and $I$ are the incident light intensity and the intensity of light passed through the layer, on the basis of the Bouguer-Lambert law. The evaluation was carried out for the maximum and minimum absorptions of the components. For the TCNQ layer $120 \mathrm{~nm}$ in thickness and in the TCNQ absorption interval, we obtained $L_{a} / d=1.9-2.7$ and $I / I_{0}=0.59-0.69$, i.e. the minimum light penetration depth $L_{a}$ exceeded the layer thickness, and the minimum intensity of light at the interface amounted to $59 \%$ of the intensity incident on the heterostructure. In the case of back heterostructure illumination (light passed through the TC layer), we obtained that $L_{a} / d=1.7-4.8$ and $I / I_{0}=0.56-0.81$. This means that the photogeneration of nonequilibrium charge carriers took place in the whole heterostructure volume, irrespective of the illumination direction.

It was suggested [4] that, in TC films, $V_{f}$ and $V_{r}$ are the algebraic sums of three photo-emfs: $V_{\mathrm{D}}, V_{b}$, and $V_{t}$. The Dember photo-emf $V_{\mathrm{D}}$ is associated with the diffusion of nonequilibrium holes toward the dark surface of the film. Its magnitude can be estimated by the formula [40]

$V_{\mathrm{D}}=\frac{k T}{q} \alpha d$

where $k$ is the Boltzmann constant, $T$ the absolute temperature, $q$ the electron charge, $\alpha$ the absorption coefficient, and $d$ the film thickness. From this formula, it follows that the $V_{\mathrm{D}}$-spectrum correlates with the film absorption spectrum, and the magnitude of $V_{\mathrm{D}}$ increases with the growth of $d$.

The barrier photo-emf $V_{b}$ is a result of the energy band bending near the film surface. The surface photo-emf $V_{t}$ is determined by the sign and magnitude of the charge captured at the surface film states. It has to be noted that the charge at the TC film surface affects the band bending. Therefore, in what follows, the sum of the $V_{b}$ and $V_{t}$ components will be referenced to as the surface-barrier photo-emf $V_{s}$ (frontal or rear).

It was found [41] that the band bending near the free surface in the TC films is locking for nonequilibrium holes. The bend magnitude decreases with the growth of the illumination intensity $H$, so that the bending can become antilocking at large $H$. The assumption was made that those changes result from the formation of tetraoxytetracene (TOT) and weak CT complexes TC-TOT and TC- $\mathrm{O}_{2}$.

In this work, we found that $V_{f}<0$ at the illuminated surface. This fact means that $V_{s f}$ and $V_{D f}$ have the same sign. In addition, $V_{f}$ decreases with the growth of $d$ (Fig. 4, curve 2; Fig. 5, curves 2 and 4). Therefore, $V_{D f} \ll V_{s f}$, and $V_{f}$ changes due to a reduction of the $V_{s f}$ magnitude. The latter takes place owing to a modification of the free surface morphology and a reduction of the surface charge, when the thickness $d$ of TC films grows.

The electron work function amounts to $4.5-4.7 \mathrm{eV}$ for ITO [42], and to $5.31 \mathrm{eV}$ for the TC crystal [32]. This fact means that the energy band bending in the TC film near the rear ITO electrode is locking for holes. Near this electrode, nonequilibrium holes recombine with electrons from the external section of the circuit, and the front ITO electrode becomes charged positively, when the free surface of the TC film is illuminated. Since the signs of $V_{f}$ and $V_{r}$ in TC films are mainly negative, this fact testifies that $V_{s f}$ provides the dominating contribution to them.

The change of the photocurrent sign was observed for TC crystals [2] and thick TC films $1.6 \mu \mathrm{m}$ in thickness [43]. In work [43], this anomaly was explained on the basis of the transfer equation [1], and the conclusion was drawn that, in TC films, either the surface recombination rate of nonequilibrium charge carriers is very high or excitons mainly annihilate in the bulk rather than at the surface of those films. In this case, the photovoltaic current polarity is determined by the type of charge carriers and the direction of their motion.

In this work, the change of the $V_{r}$ sign was observed at an air pressure of $10^{5} \mathrm{~Pa}$ in the measurement cell, but only for the thinnest $(120 \mathrm{~nm}) \mathrm{TC}$ film (Fig. 4, curve 4). This spectrum considerably changed, when the air pressure in the cell was lowered down to $10^{2} \mathrm{~Pa}$ (Fig. 4, curve 5). One may assume that $V_{r}$ changes its sign in the thinnest films owing to the formation of CT complexes between TC molecules and oxygen, which agrees with the results of work [41] and is confirmed by the existence of a weak $\mathrm{TC}^{+}$band at $1.799 \mathrm{eV}$ in the absorption spectra (Fig. 4, curve 1). In the case of a thicker TC film, the absence of this band (Fig. 5, curve 1) testifies to a small number of CT complexes, and no sign change 
was observed for it. The analysis of our results and the literature data cited above $[2,43]$ demonstrates that there is no general approach to the explanation of the origin of the sign variation in thin TC films. This anomaly will be studied in our further researches.

Since TC and TCNQ are semiconductors of the $p$ - and $n$-types, respectively, there emerges a double electric layer at the interface between the heterostructure components, which is formed by electrons and holes from the TC and TCNQ surfaces, respectively. The electric field of this heterojunction (HJ) governs the drift of nonequilibrium holes and electrons toward the rear ITO electrode and the free surface of TCNQ layer, respectively.

The largest peak values of $V_{f}$ and $V_{r}$ in heterostructures with a component thickness of $120 \mathrm{~nm}$ were observed at photon energies of 2.995 and $2.823 \mathrm{eV}$ (Fig. 6, curves 2 and 4). The former value is close to the forbidden gap width in TC and to the energy of the first electron transition in the $\mathrm{TCNQ}^{0}$ molecule, i.e. nonequilibrium charge carriers of both signs contribute to the $V_{f^{-}}$and $V_{r}$-values in heterostructures at $E \geq 2.995 \mathrm{eV}$. At the same time, electrons are generated by light in the layers of both components. Photon energies of 2.823 and $2.843 \mathrm{eV}$ in the $V_{f}$ and $V_{r}$ spectra are close to the energy of the first electron transition in $\mathrm{TCNQ}^{-}[4,18,39]$. In heterostructures, $\mathrm{TCNQ}^{-}$anion-radicals can be formed both in the bulk of a TCNQ layer and near the component interface (Fig. 6, curves 3 and 5). A reduction of the air pressure in the cell to $10^{2} \mathrm{~Pa}$ results in decreases of the $V_{f}$ and $V_{r}$ in heterostructures, similarly to the case of TC films (Fig. 4, curves 3 and 5), which testifies that those heterostructures contained CT complexes of TC with oxygen.

The $V_{f}$ and $V_{r}$ spectra for the heterostructure with a thickness of $170 \mathrm{~nm}$ for each of its layers (the inset in Fig. 7) differ by the distribution of peak band intensities from the corresponding spectra in the case where the thicknesses of the layers amount to $120 \mathrm{~nm}$ (Fig. 6). In the $V_{f}$ spectrum for the heterostructure with thicker layers, the band at $2.828 \mathrm{eV}$ can be associated with $\mathrm{TCNQ}^{-}$, and the bands at 2.352 and $2.537 \mathrm{eV}$ have the maximum peak intensities. In the $V_{r}$ spectrum, this is the band at $2.405 \mathrm{eV}$. Additionally, long-wave bands are observed, among which the bands at 1.989 and $2.216 \mathrm{eV}$ should be distinguished (by their position, they are close to the $\mathrm{TCNQ}^{-}$dimer absorption bands (Fig. 2, curve 3)), as well as the band at $2.155 \mathrm{eV}$ with the opposite sign. For the heterostructure under the frontal illumination (the inset in Fig. 7), $L_{a} / d=0.9 \div 2.0$ and $\left.I / I_{0}=0.33 \div 0.61\right)$, whereas, under the rear illumination, $L_{a} / d=0.88 \div 3.4$ and $I / I_{0}=0.32 \div 0.74$. As a result, $L_{a}$ is smaller than the thickness of the TCNQ layer at the frontal illumination and the thickness of the TC layer at the rear illumination only in the cases of photons with energies of 2.216 and $2.461 \mathrm{eV}$. Furthermore, the minimum relative light intensity at the component interface amounts to $32 \%$, i.e. the photogeneration of nonequilibrium charge carriers occurs in the whole volume of those heterostructures, irrespective of the illumination direction.

It was found that the free surface of the TCNQ film in the heterostructures becomes charged negatively at the front illumination. This fact means that nonequilibrium electrons drift to the TCNQ film surface and nonequilibrium holes to the rear ITO electrode under the action of the electric field in the heterostructure. We may assume that the photo-emf $V_{H}$ dominates in the front and rear photo response of heterostructures.

In the $V_{f}$ and $V_{r}$ spectra of the composite (Fig. 7, curves 1 and 3 ), the intensities of long-wave bands are larger in comparison with those for the heterostructure (the inset in Fig. 7). At the same time, there is no sign change in those spectra, and the band at $2.402 \mathrm{eV}$ in the $V_{f}$ spectrum and the band at $2.481 \mathrm{eV}$ in the $V_{r}$ spectrum have the maximum peak intensities. The CT complexes of TC with TCNQ also contribute to the $V_{f}$ and $V_{r}$ spectra of heterostructures and composites, which is testified by the $\mathrm{TC}^{+}$ bands at 1.67 and $2.06 \mathrm{eV}$ (Fig. 7). In the $V_{f}$ and $V_{r}$ spectra of composites, the intensities of the indicated bands are higher than in the case with heterostructures, i.e. the number of CT complexes in the composites is larger, which is a necessary condition for the creation of TC + TCNQ cocrystals.

\section{Conclusions}

In this work, it is found that the films of TC, TCNQ, TC/TCNQ heterostructures, and TC + TCNQ composites, which were sputtered in a vacuum of $6.6 \mathrm{mPa}$ onto glass substrates, are polycrystalline. The linear size of crystallites in those films did not exceed $1 \mu \mathrm{m}$. Changes in the structure of TCNQ films in the heterostructures in comparison with the structure of 
TCNQ films on glass substrates occur due to the influence of molecules in the lower TC layer.

The largest variations of $\Delta D_{1}$ in the absorption spectra of heterostructures and composites in comparison with the sum of absorption contributions given separately by the components are observed in the intervals of TCNQ dimer bands at $2.214 \mathrm{eV}$ $\left(\Delta D_{1}<0\right)$ and in all TC bands $\left(\Delta D_{1}>0\right)$. Those variations testify to the formation of charge transfer (CT) complexes between the TC (the electron donor) and TCNQ (the electron acceptor) molecules at the heterostructure interface and in the composite bulk. It is found that the TCNQ films have a low photosensitivity, which is comparable with measurement errors. The spectra of the photovoltaic response of the TC/TCNQ heterostructure and TC + TCNQ composite films at their front and rear illumination are registered in the absorption interval of TC films.

Higher intensities of the bands at 1.737 and $2.021 \mathrm{eV}$ belonging to the $\mathrm{TC}^{+}$cation-radical in the $V_{f}$ and $V_{r}$ spectra of composites in comparison with those for heterostructures, as well as the bands at 2.828 and $2.896 \mathrm{eV}$ belonging to the $\mathrm{TCNQ}^{-}$anionradical, testify to the formation of TC + TCNQ cocrystals in the composite bulk, when the TC and TCNQ components are simultaneously sputtered in vacuum.

The work was carried out in the framework of the NASU scientific project No. 14B/186.

1. N. Geacintov, M. Pope, H. Kallman. Photogeneration of charge carriers in tetracene. J. Chem. Phys. 45, 2639 (1966).

2. P.J. Reucroft, P.L. Kronick, E.E. Hillman. Photovoltaic effects in tetracene crystals. Mol. Cryst. Liq. Cryst. 6, 247 (1969).

3. M. Campione, D. Braga, L. Raimondo, M. Moret, A. Sassella, S. Binetti, M. Acciarri. The photovoltaic response of intrinsic organic semiconductor single crystals. Open Appl. Phys. J. 3, 17 (2010).

4. M.P. Gorishnyi, A.B. Verbitsky. Structural, optical, and photovoltaic properties of tetracene thin films. Ukr. J. Phys. 6, 50 (2016).

5. C.-W. Chu, Y. Shao, V. Shrotriua, Y. Yang. Efficient photovoltaic energy conversion in tetracene- $\mathrm{C}_{60}$ based heterojunctions. Appl. Phys. Lett. 86, 243506 (2005).

6. Y. Shao, S. Sista, C.-W. Chu, D. Sievers, Y. Yang. Enhancement of tetracene photovoltaic devices with heat treatment. Appl. Phys. Lett. 90, 103501 (2007).
7. R.J. Tseng, R. Chan, V.C. Tung, Y. Yang. Anisotropy in organic single-crystal photovoltaic characteristics. Adv. Mater. 20, 435 (2008).

8. J.-M. Choi, J. Lee, D.K. Hwang, J.H. Kim, S. Im, E. Kim. Comparative study of the photoresponse from tetracenebased and pentacene-based thin-film transistors. J. Appl. Phys. Lett. 88, 043508 (2006).

9. Y. Xia, V. Kalinari, C.D. Frisibie, N.K. Oh, J.A. Rogers. Tetracene air-gap single-crystal field-effect transistors. J. Appl. Phys. Lett. 90, 162106 (2007).

10. R. Sarma, D. Saikia. Study of tetracene thin film transistors using $\mathrm{La}_{2} \mathrm{O}_{3}$ as gate insulator. Indian J. Pure Appl. Phys. 47, 876 (2009).

11. M.M. Islam. Self-assemble monolayer dependent field effect transistors performance based on tetracene single-crystal. J. Bangladesh Chem. Soc. 25 (2), 194 (2012).

12. A. Hepp, H. Heil, W. Weise, M. Ahles, R. Schmechel, H. von Seggern. Light-emitting field-effect transistor based on a tetracene thin film. Phys. Rev. Lett. 91, 157406 (2003).

13. J. Renynaert, D. Cheyns, D. Janssen, R. Müller, V.I. Arkhipov, J. Genoe, G. Borghs, P. Heremans. Ambipolar injection in a submicron-channel light-emitting tetracene transistor with distinct source and drain contacts. J. Appl. Phys. 97, 114501 (2005).

14. Y. Ohshima, H. Satou, N. Hirako, H. Kohn, T. Manaka, M. Iwamoto. Direct observation of carrier behavior leading to electroluminescence in tetracene field-effect transistor. Jpn. J. Appl. Phys. 50, 04Dk14 (2011).

15. D.S. Acker, R.J. Harder, W.R. Hertler, W. Mahler, L.R. Melbv, R.E. Benson, W.E. Mochel. 7,7,8,8-tetracyanoquinodimethane and its electrically conducting anionradical derivatives. J. Am. Chem. Soc. 82, 6408 (1960).

16. J. Ferraris, D.O. Cowan, V. Walatka, J.H. Perlstein. Electron transfer in a new highly conducting donor-acceptor complex. J. Am. Chem. Soc. 95, 948 (1973).

17. H.T. Jonkman, J. Kommandeur. The UV spectra and their calculation of TCNQ and its mono- and di-valent anion. Chem. Phys. Lett. 15 (4), 496 (1972).

18. M.P. Gorishnyi. Electron energy structure of the tetracyano-quinodimethane molecule in the neutral and anionradical states. Ukr. J. Phys. 49, 1158 (2004).

19. K. Kojima, A. Maeda, M. Ieda. Electrical properties of TCNQ evaporated thin films. In Proceedings of the $3 r d$ International Conference on Properties and Applications of Dielectric Materials, Tokyo, 8-12 July 1991, Vol. 1, p, 185 (1991).

20. T. Oyamada, H. Tanaka, K. Matsushide, H. Sasabe, Ch. Adachi. Switching effect in $\mathrm{Cu}$ : TCNQ charge transfercomplex thin films by vacuum codeposition. Appl. Phys. Lett. 83, 1252 (2003).

21. X.-L. Mo, G.-R. Chen, Q.-J. Cai, Zh.-Y. Fan, H.-H. Xu, Y. Yao, J. Yang, H.-H. Gu, Zh.-Y. Hua. Preparation and electrical/optical bistable property of potassium tetra- 
cyanoquinodimethane thin films. Thin Solid Films 436 , 259 (2003).

22. Z. Fan, X. Mo, C. Lou, Y. Yao, D. Wang, G. Chen, J.G. Lu. Structures and electrical properties of Ag-tetracyanoquinodimethane organometallic nanowires. IEEE Trans. Nanotechnol. 4 (2), 238 (2005).

23. K. Xiao, I.N. Ivanov, A.A. Puretzky, Z. Liu, D.B. Geohegan. Directed integration of tetracyanoquinodimethane- $\mathrm{Cu}$ organic nanowires into prefabricated device architectures. Adv. Mater. 18, 2184 (2006).

24. M.P. Gorishnyi, O.V. Kovalchuk, T.N. Kovalchyk, A.B. Verbitsky, V.E. Vovk. Optical and photoelectric properties of heterostructures of fullerene $\mathrm{C}_{60}$ with phthalocyanines and tetracyanoquinodimethane (TCNQ). Mol. Cryst. Liq. Cryst. 535, 49 (2011).

25. H. Gao, Z. Xue, Q. Wu. Chin. Electrical phenomena of C-tetracyanoquinodimethane thin films. Chin. Phys. Lett. 11, 766 (1994).

26. T. Sumimoto, M. Tisuka, S. Kunivoshi, K. Kudo, K. Tanaka, Y.H. Yu. In-situ field effect measurements of copper phthalocyanine films doped with acceptor molecule. J. Korean Phys. Soc. 31, 522 (1997).

27. R. Ishikawa, M. Baudo, Y. Morimoto, A. Sandhu. Doping graphene films via chemically mediated charge transfer. Nanoscale Res. Lett. 6, 111 (2011).

28. A.J.C. Buurma, O.D. Jurchescu, I. Shokaryev, J. Baas, A. Meetsma, G.A. de Wijs, R.A. de Groot, T.T.M. Palstra. Crystal growth, structure, and electronic band structure of tetracene-TCNQ. J. Chem. Phys. C 111 (8), 3486 (2007).

29. I. Shokaryev, A.J.C. Buurma, O.D. Jurchescu, M.A. Uijttewaal, G.A. de Wijs, T.T.M. Palstra, R.A. de Groot. Electronic band structure of tetracene-TCNQ and peryleneTCNQ compounds. J. Chem. Phys. A 112, 2497 (2008).

30. P. Hu, H. Li, Y. Li, Ch. Kloc. Single-crystal growth, structures, charge transfer and transport properties of anthracene- $\mathrm{F}_{4} \mathrm{TCNQ}$ and tetracene- $\mathrm{F}_{4}$ TCNQ chargetransfer compounds. Cryst. Eng. Commun. 19, 618 (2017).

31. M. Sakai, M. Iizuka, M. Nakamura, K. Kudo. Fabrication and electrical characterization of tetrathiafulvalenetetracyanoquinodimethane molecular wires. Jpn. J. Appl. Phys. 42, N 4B, 2488 (2003).

32. E.A. Silinsh, M.V. Kurik, V. Capek, Electronic Processes in Organic Molecular Crystals. Localization and Polarization Phenomena (Zinatne, 1988) (in Russian).

33. R.H. Boyd, W.D. Philips. Solution dimerization of the tetracyanoquinodimethane ion radical. J. Chem. Phys. 43, 2927 (1965)

34. M.P. Gorishnyi. Electron structure of tetrathiatetracene and photo-electric properties of heterostructures on its basis. Ph.D. thesis (Lviv, 1990) (in Russian).

35. H. Kuroda, S. Hiroma, H. Akamatu. Polarized absorption spectra of single crystals of ion radical salts. I. Molecular compounds of 7,7,8,8-tetracyano-p-quinodimethane with $N, N, N^{\prime}, N^{\prime}$-tetramethyl-p-phenylenediamine and $N, N$ dimethyl-p-phenylenediamine. Bull. Chem. Soc. Jpn. 41, 2855 (1968)
36. S. Hiroma, H. Kuroda, H. Akamatu. Semiconductivity and photoconductivity of TCNQ crystal. Bull. Chem. Soc. Jpn. 44, 974 (1971).

37. Y. Iida. Electronic spectra of crystalline TCNQ anion radical salts. I. Simple salts. Bull. Chem. Soc. Jpn. 42, 71 (1969).

38. Y. Iida. Electronic spectra of crystalline TCNQ anion radical salts. II. Complex salts. Bull. Chem. Soc. Jpn. 42, 637 (1969).

39. L. Ma, P. Hu, H. Jang, C. Kloc, H. Sun, C. Soci, A.A. Voityuk, M.E. Michel-Beyerle, G.G. Gurzadyan. Single photon triggered dianion formation in TCNQ and F4TCNQ crystals. Sci. Rep. 6, 28510 (2016).

40. M.P. Gorishnyi. Photoeffect in polythiopentacene films and influence of permanent illumination on it. Ukr. J. Phys. 52, 1154 (2007)

41. Ya.I. Vertsimakha, Yu.M. Lopatkin. Influence of photoirradiation on the photoelectric properties of tetracene films. Fundam. Osn. Opt. Pamyat. Sredy No. 15, 49 (1984) (in Russian).

42. R. Schlaf, H. Murata, Z.H. Kafafi. Work function measurements on indium tin oxide films. J. Electr. Spectrosc. Rel. Phenom. 120, 149 (2001).

43. P.H. Fang, A. Golubovic, N.A. Dimond. Photovoltaic current anomaly in naphthacene. Jpn. J. Appl. Phys. 11, 1298 (1972)

Received 28.06.17

Translated from Ukrainian by O.I. Voitenko

\section{М.П. Горішний, А.Б. Вербичъкий}

\section{ДОНОР-АКЦЕПТОРНА ВЗАЄМОДІЯ}

В ПЛІВКАХ ГЕТЕРОСТРУКТУР I КОМПОЗИТІВ ТЕТРАЦЕНА ІЗ ТЕТРАЦІАНХІНОДИМЕТАНОМ

Р е $з$ ю м е

Досліджено структуру, спектри поглинання і фотовольтаїчний відгук тонких плівок тетрацену(Тc), тетраціанхінодиметану (TCNQ), гетероструктур (ГC) Tc/TCNQ і композитів Tc+TCNQ. ГC і композити одержано послідовним і одночасним вакуумним термічним напорошенням компонент відповідно. Фотовольтаїчний відгук виміряно конденсаторним методом. Вперше встановлено, що найбільші зміни $\Delta D_{1}$ в спектрах поглинання $\Gamma \mathrm{C}$ і композитів порівняно із таким для суми поглинання компонент спостережено в областях димерних смуг TCNQ $2,214 \mathrm{eB}\left(\Delta D_{1}<0\right)$ i всіх смуг Тс $\left(\Delta D_{1}>0\right)$. Ці зміни свідчать про утворення на межі розподілу ГС і в об'ємі композитів СТ-комплексів (charge transfer complexes) між молекулами Тс (донор) i TCNQ (акцептор електронів), що підтверджується також появою смуг $\mathrm{Tc}^{+}$i $\mathrm{TCNQ}^{-}$в спектрах фотовідгуку $\Gamma \mathrm{C}$ i композитів. Цей результ є важливим для більш глибокого розуміння принципів роботи потенційно можливих різних пристроїв на основі цих ГС і композитів (сонячних елементів, польових транзисторів і світлодіодів).

ISSN 2071-0194. Ukr. J. Phys. 2018. Vol. 63, No. 1 